\title{
The Type I Inositol 1,4,5-Trisphosphate Receptor Interacts with Protein 4.1N to Mediate Neurite Formation through Intracellular $\mathrm{Ca}^{2+}$ Waves
}

\author{
Michael J. Fiedler Michael H. Nathanson \\ Cell Biology Department, Yale University, New Haven, Conn., USA
}

\section{Key Words}

Type I inositol 1,4,5-trisphosphate receptor - Protein 4.1N • $\mathrm{Ca}^{2+}$ waves $\cdot$ Neuron

\begin{abstract}
$\mathrm{Ca}^{2+}$ waves are an important mechanism for encoding $\mathrm{Ca}^{2+}$ signaling information, but the molecular basis for wave formation and how this regulates neuronal function is not entirely understood. Using nerve growth factor-differentiated PC12 cells as a model system, we investigated the interaction between the type I inositol 1,4,5-trisphosphate receptor (IP3R1) and the cytoskeletal linker, protein $4.1 \mathrm{~N}$, to examine the relationship between $\mathrm{Ca}^{2+}$ wave formation and neurite development. This was examined using RNAi and overexpressed dominant negative binding regions of each protein. Confocal microscopy was used to monitor neurite formation and $\mathrm{Ca}^{2+}$ waves. Knockdown of IP3R1 or $4.1 \mathrm{~N}$ attenuated neurite formation, as did binding regions of IP3R1 and 4.1N, which colocalized with endogenous $4.1 \mathrm{~N}$ and IP3R1, respectively. Upon stimulation with the IP3-producing agonist carbachol, both RNAi and dominant negative molecules shifted signaling events from waves to homogeneous patterns of $\mathrm{Ca}^{2+}$ release. These findings provide evidence that IP3R1 localization, via protein $4.1 \mathrm{~N}$, is necessary for $\mathrm{Ca}^{2+}$ wave formation, which in turn mediates neurite formation.
\end{abstract}

Copyright ๑ 2011 S. Karger AG, Basel

\section{KARGER}

Fax +4161306 1234

E-Mail karger@karger.ch

www.karger.com
(C) 2011 S. Karger AG, Basel

Accessible online at: www.karger.com/nsg

\section{Introduction}

$\mathrm{Ca}^{2+}$ signals regulate a wide range of functions in neurons, including exocytosis of synaptic vesicles $[1,2]$, extension of neural growth cones [3, 4], and gene transcription [5]. Complex temporal and spatial features of $\mathrm{Ca}^{2+}$ signals, such as $\mathrm{Ca}^{2+}$ oscillations and waves, are thought to encode important signaling information [6, 7]. The inositol $(1,4,5)$-trisphosphate (IP3) receptor (IP3R) is the principal intracellular $\mathrm{Ca}^{2+}$ release channel in most cells, and the expression and subcellular distribution of its isoforms regulate $\mathrm{Ca}^{2+}$ wave formation [8-10]. This particular $\mathrm{Ca}^{2+}$ signaling pattern is thought to be important for neuronal processes such as synaptic plasticity [11], and non-neuronal processes such as axis formation [12], differentiation [13], motility [14], fluid and electrolyte secretion [15], and epithelial polarity [16]. However, the mechanisms by which IP3Rs are spatially segregated to facilitate $\mathrm{Ca}^{2+}$ wave formation are not entirely understood. Protein $4.1 \mathrm{~N}$ is a cytoskeletal associated protein expressed in neurons that binds to the type I IP3R (IP3R1), targeting it to the subplasmalemmal space $[17,18]$. Moreover, the interaction between protein $4.1 \mathrm{~N}$ and IP3R1 regulates lateral diffusion of this $\mathrm{Ca}^{2+}$ channel within neuronal dendrites [19]. The goal of this work was to determine the importance of this interaction for $\mathrm{Ca}^{2+}$ wave formation in neurons, and to determine the relevance of these $\mathrm{Ca}^{2+}$ waves for a specific $\mathrm{Ca}^{2+}$-mediated event, neurite formation. 


\section{Materials and Methods}

Mammalian Tissue Culture and Differentiation Conditions

PC12 cells were grown in F-12K media (ATCC), 2.5\% fetal bovine serum (ATCC), 15\% horse serum (ATCC), and 1\% penicillin/ streptomycin (Gibco). Cells were differentiated with $7 \mathrm{~S}$ nerve growth factor (100 ng/ $\mu \mathrm{l}$; Sigma) for $24-48 \mathrm{~h}$.

\section{Molecular Biology and Transient Transfections}

Dominant negative constructs were generated using IP3R1 and protein $4.1 \mathrm{~N}$ plasmid constructs $[18,19]$. Primers for the IP3R1 dominant negative were: 5'-GCGCAAGCTTCACCTTTGCTGACCTGAG-3' and 5'-GCGCGAATTCCTAGGCCGGCTGCTGTGG-3'. Primers for protein $4.1 \mathrm{~N}$ were: $5^{\prime}$-GCGCGAATTCTCCAGGCCCACAGAC- $3^{\prime}$ and $5^{\prime}$-GCGCGGATCCTCAGGATTCCTGTGGCTTCTTGTC-3'. Primers were introduced into a C1-DsRed-Express Vector (Clontech). Silencer ${ }^{\circledR}$ Select siRNA (Applied Biosystems) corresponded to IP3R1, protein 4.1N, IP3R3, or scrambled negative control. PC12 cells were transfected using Lipofectamine (Invitrogen). DNA plasmids were incubated in PC12 cells for $48 \mathrm{~h}$ and RNAi molecules for $72 \mathrm{~h}$.

\section{Immunoblots}

Blots were performed as described [20]. For IP3R1 blots, $35 \mu \mathrm{g}$ of protein lysate was combined with $5 \times$ loading buffer $/ \beta$-mercaptoethanol in $<50 \mu \mathrm{l}$ and subjected to SDS PAGE electrophoresis. Protein $4.1 \mathrm{~N}$ and IP3R3 blots were done with 100 and $80 \mu \mathrm{g}$ of protein, respectively. For M1 and M5 muscarinic receptor blots, $100 \mu \mathrm{g}$ of protein was used. Protein lysate was transferred to PVDF membranes then blocked using Tris buffer saline and $0.1 \%$ Tween-20 plus $5 \%$ milk. IP3R1 blots used a rabbit primary polyclonal antibody (Upstate) at a concentration of 1:5,000. Protein 4.1N and IP3R3 blots used monoclonal primary antibodies (BD Biosciences) at a concentration of 1:1,000. M1 and M5 blots used polyclonal antibodies (Novus Biologicals and Abcam, respectively) at a concentration of 1:400. Blots were visualized by chemiluminescence.

\section{Immunofluorescence and Confocal Microscopy}

PC12 cells were fixed in paraformaldehyde, then permeabilized/blocked with $1 \times$ phosphate-buffered saline, $0.01 \%$ Tween-20, $1 \%$ bovine serum albumin, and 5\% normal goat serum. Cells were stained with primary antibodies at a dilution of 1:100, then washed and stained with fluorescently labeled secondary antibodies [21]. TO-PRO-3 (Invitrogen) was used for nuclear staining. A Zeiss LSM 510 confocal microscope was used for imaging. Scale bar $=10 \mu \mathrm{m}$.

\section{Neurite Quantification}

Neurites were quantified as described [22]. Briefly, immunofluorescence images were obtained of fields of nerve growth factor (NGF)-stimulated cells. The length of each neurite was measured and the number of nuclei was counted. Total neurite length in each field was then divided by the number of nuclei in the same field to determine average neurite length per cell ( $\mu \mathrm{m} / \mathrm{nuclei})$. At least 150 cells were included per experiment and experiments were performed in triplicate. For dominant negative studies, only transfected cells were counted.

\section{$\mathrm{Ca}^{2+}$ Signaling}

PC12 cells stimulated with NGF for 0,24 , or $48 \mathrm{~h}$ were studied. Cells were placed in serum-free F-12K media, then loaded with $6 \mu \mathrm{M}$ Fluo-4AM (Invitrogen) and perfused with a Hepes buffer while stimulated with $50 \mu \mathrm{M}$ carbachol (CCH, Sigma ca No. 4382) and visualized with a Zeiss LSM 510 confocal microscope. Regions of interest (ROIs) in the neurite and soma were analyzed using ImageJ. To quantify the delay between $\mathrm{Ca}^{2+}$ signals in the neurite and soma, the percentage of the maximum amplitude in the soma was calculated when the amplitude of the signal in the neurite was at half-maximum. Between 15 and 30 cells were used for each condition.

\section{Statistics}

Significance of differences was determined by either Student $t$ test or one-way analysis of variance (ANOVA) using GraphPad. $\mathrm{p}<0.05$ was taken to indicate a statistically significant difference.

\section{Results}

\section{Expression and Colocalization of IP3R1 and Protein $4.1 \mathrm{~N}$}

The subcellular distribution of IP3R 1 and protein $4.1 \mathrm{~N}$ in neurons was determined through immunolabeling of endogenously expressing primary hippocampal neurons (fig. 1A). IP3R1 localized along the dendritic processes of these neurons as well as in the soma, but not in the nucleus. $4.1 \mathrm{~N}$ was limited to the periphery of the soma and the dendritic processes. IP3R1 and $4.1 \mathrm{~N}$ strongly colocalized, particularly in the dendrites. Expression of these two proteins was examined by Western blot in mouse cerebral cortex, PC12, and HEK293 cells (fig. 1B). Both IP3R1 and $4.1 \mathrm{~N}$ were detected in primary neuronal tissue as well as in PC12 cells, a model system for neuronal development [23]. HEK293 cells expressed only IP3R1. Because NGF [14] mediates the neuronal phenotype of PC12 cells, expression of IP3R1 and 4.1N was measured at 0, 24, and $48 \mathrm{~h}$ of NGF stimulation (fig. 1C). Expression of IP3R1 was similar at each time point, as was $4.1 \mathrm{~N}$, consistent with previous studies [24]. To complement these expression studies, immunofluorescent staining of IP3R1 and $4.1 \mathrm{~N}$ was performed at identical time points (fig. 1D). Before stimulation with NGF, IP3R1 and $4.1 \mathrm{~N}$ colocalized along the periphery of PC12 cells, and cells exhibited a spherical morphology. At $24 \mathrm{~h}$ of NGF stimulation, PC12 cells adopted a partial neuronal appearance with the development of budding neurites. At this time point, IP3R1 and $4.1 \mathrm{~N}$ continued to colocalize along the cell periphery. After $48 \mathrm{~h}$ of NGF stimulation, prominent neurites were visualized, which resemble the morphology of primary hippocampal neurons. At this stage, the pattern of colo- 


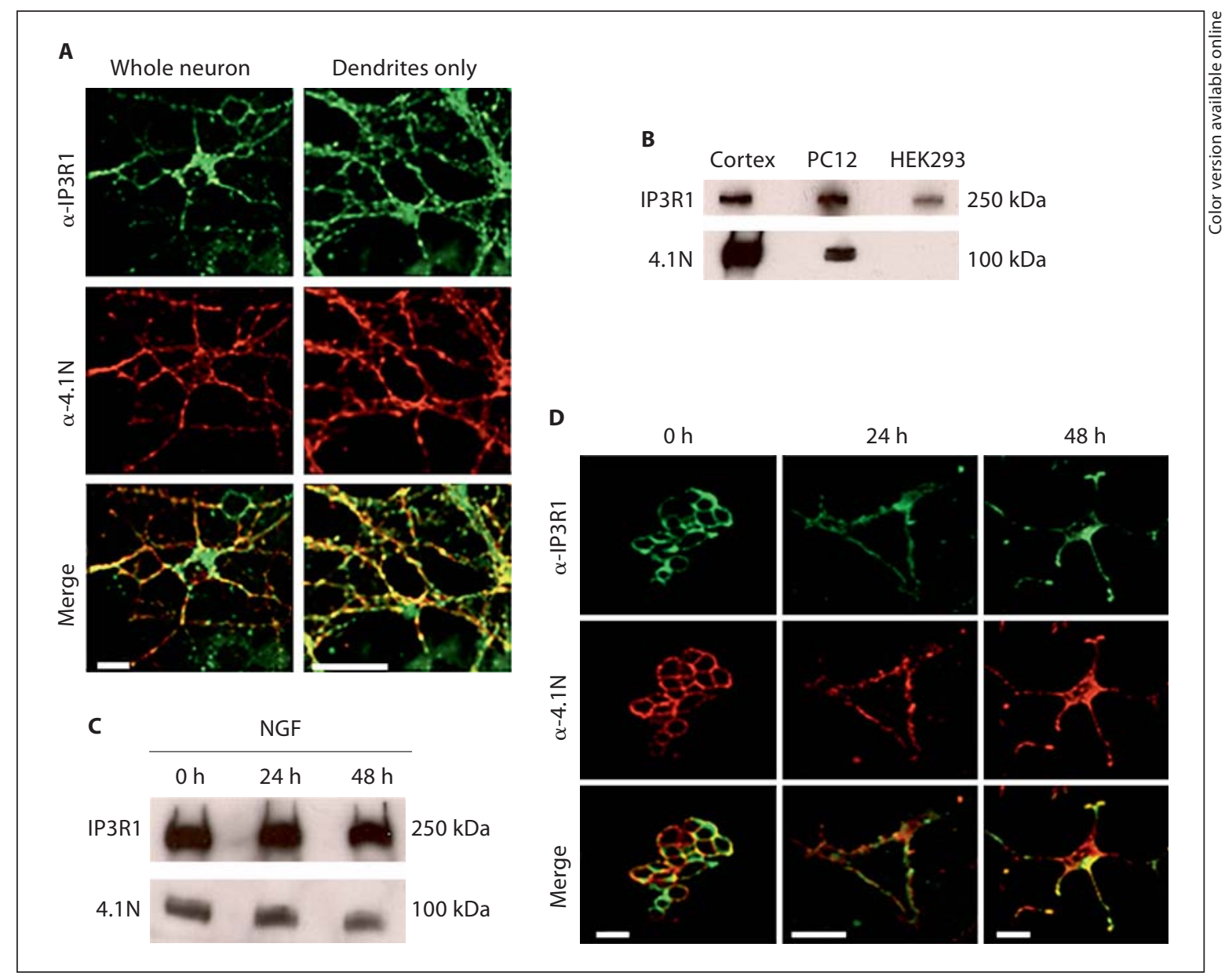

Fig. 1. Localization and expression of IP3R 1 and protein $4.1 \mathrm{~N}$ in primary and tissue culture cells. A Confocal images of primary hippocampal neurons immunolabeled with antibodies against IP3R1 and protein 4.1N. Left column: single hippocampal neuron. Right column: dendritic processes only. IP3R1 is localized to both the soma and dendritic processes. Protein $4.1 \mathrm{~N}$ is localized along cell periphery and within dendritic processes. Colocalization (yellow) shown in the merged image. B IP3R1 and protein $4.1 \mathrm{~N}$ Western blots from mouse total cortex, PC12 cells, and
HEK293 cells. IP3R1 is expressed in both neuronal (cortex and PC12) and non-neuronal (HEK293) cells but protein $4.1 \mathrm{~N}$ is not expressed in HEK293 cells. C Western blot of IP3R1 and protein 4.1N from PC12 cells 0, 24, and 48 h after NGF stimulation. Expression of both proteins is similar at each time point. D Immunofluorescent images of IP3R 1 and protein $4.1 \mathrm{~N}$ in PC12 cells 0 , 24 , and $48 \mathrm{~h}$ after NGF stimulation. Regions of colocalization can be appreciated in merged images (yellow). Colors refer to the online version only. calization between IP3R1 and $4.1 \mathrm{~N}$ was similar to what was observed in neuronal processes in primary neurons. Together, these findings suggest that PC12 cells serve as a model cell system to investigate the IP3R1/protein $4.1 \mathrm{~N}$ interaction in developing neurons.

\section{RNAi Knockdown of IP3R1 and Protein 4.1N, but Not} IP3R3, Attenuates Neurite Formation

To determine the functional significance of IP3R 1 and protein $4.1 \mathrm{~N}$ expression and colocalization, RNAi experiments were performed to selectively knock down each protein in cells stimulated with NGF for $48 \mathrm{~h}$. Reducing IP3R1 expression (fig. 2Aii) caused a significant decrease in neurite formation (fig. 2Aiii). In contrast, mock-transfected cells or cells transfected with scrambled (SCR) siRNA retained neurite processes, with IP3R1 and 4.1N (inset, red) localized along the cell periphery and into the neuronal extensions (fig. 2Ai). To quantify this phenotype, total neurite length $(\mu \mathrm{m})$ in a $40 \times$ field was summed and divided by the total number of cells (nuclei). Under mock and SCR transfection conditions, cells averaged $46.4 \pm 7.8$ and $40.8 \pm 2.4 \mu \mathrm{m}$ neurite length/nuclei, re- 
A i
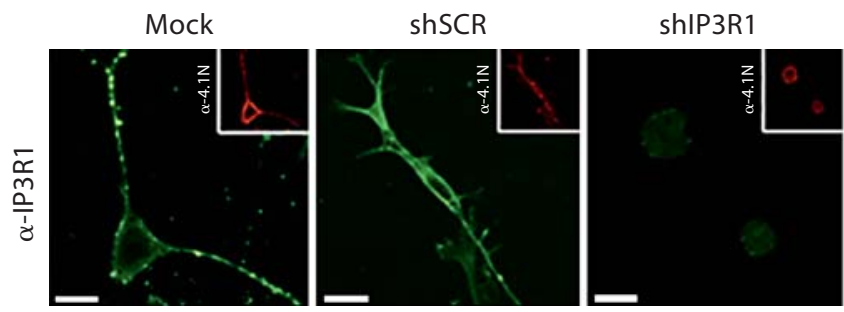

B i

Mock
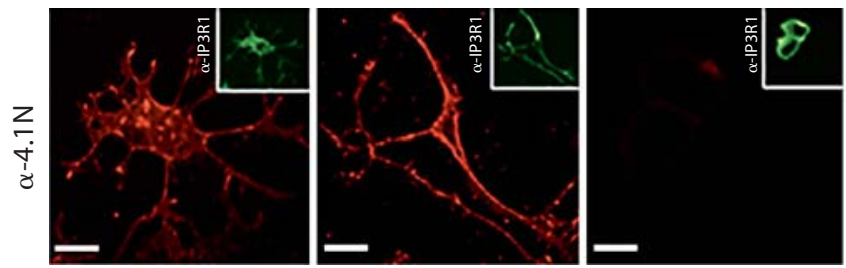

C $\mathbf{i}$
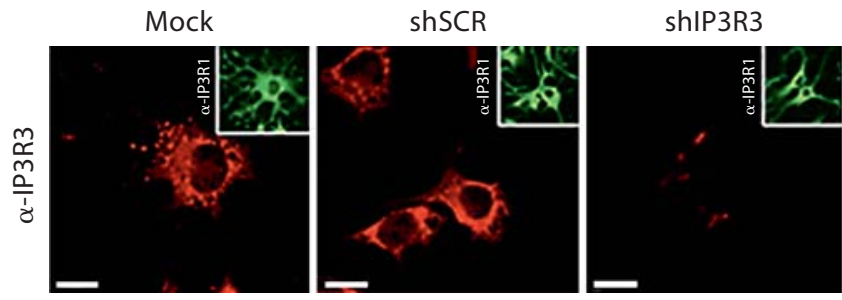

ii

iii

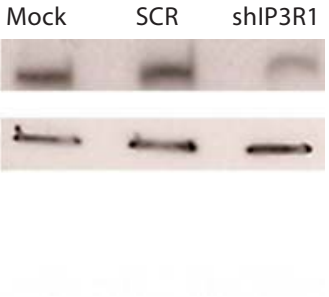

$250 \mathrm{kDa}$

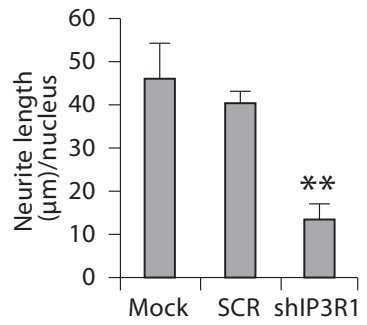

iii

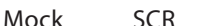

$100 \mathrm{kDa}$

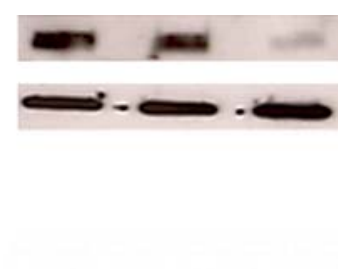

ii

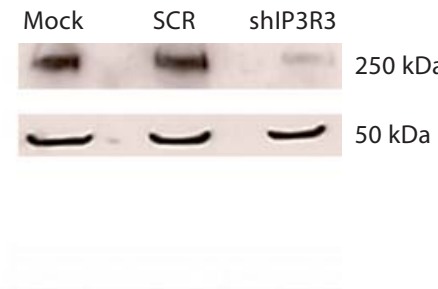

Fig. 2. RNAi knockdown of IP3R1 or protein 4.1N, but not IP3R3, attenuates neurite formation. A Confocal immunofluorescence images, immunoblot, and neurite quantification of PC12 cells stimulated with NGF for $48 \mathrm{~h}$ and IP3R1 knocked down via RNAi. i Immunofluorescence images of mock, SCR-transfected, and IP3R1 siRNA-transfected (shIP3R1) cells. Under control conditions IP3R1 and protein $4.1 \mathrm{~N}$ (inset, red) both localize along the cell periphery and in neurites. ii Immunoblot of IP3R1 from RNAi-transfected cells with $\alpha$-tubulin loading control demonstrates efficacy of knockdown. iii Neurite quantification of RNAitransfected PC12 cells with units 'average neurite length $(\mu \mathrm{m})$ per nucleus'. Average neurite lengths in nontransfected and scramble-transfected cells are $46.4 \pm 7.8$ and $40.8 \pm 2.4$, respectively, while cells transfected with shIP3R1 averaged $13.8 \pm 3.3\left({ }^{* *} \mathrm{p}<\right.$ 0.01). B Confocal immunofluorescence images, immunoblot, and neurite quantification of PC12 cells stimulated with NGF for $48 \mathrm{~h}$ and protein $4.1 \mathrm{~N}$ knocked down via RNAi. i Immunofluorescence images of mock, SCR-transfected, and protein $4.1 \mathrm{~N}$ siRNA-transfected $(\mathrm{sh} 4.1 \mathrm{~N})$ cells. Under control conditions protein $4.1 \mathrm{~N}$ and
IP3R1 (inset) localize along cell periphery and in neurites. ii Protein 4.1N RNAi Western blot with $\alpha$-tubulin used as a loading control demonstrates efficacy of knockdown. iii Neurite quantification: mock and SCR-transfected cells yield neurite length values of $41.0 \pm 13.3$ and $36.0 \pm 9.0$, respectively, while sh4.1Ntransfected cells average $11.5 \pm 2.2$ units of neurite length $\left({ }^{*} \mathrm{p}<\right.$ 0.05). C Confocal immunofluorescence images, immunoblot, and neurite quantification of PC12 cells stimulated with NGF for $48 \mathrm{~h}$ and IP3R3 knocked down via RNAi. i Immunofluorescence images of mock, SCR, and IP3R3 siRNA-transfected (shIP3R3) cells. Under control conditions IP3R3 is localized within soma and IP3R1 (inset) extends into neurites. ii IP3R3 RNAi immunoblot with $\alpha$-tubulin loading control demonstrates efficacy of knockdown. iii Neurite quantification: mock, scramble, and shIP3R3transfected cells have neurite length values of $35.6 \pm 3.9,35.9 \pm$ 19.0 , and $38.0 \pm 13.8$, respectively (difference not significant; $\mathrm{n}=$ 3,150 cells assessed per experiment). Colors refer to the online version only. 
spectively. However, under shIP3R1 transfection conditions, cells averaged $13.8 \pm 3.3 \mu \mathrm{m}$ neurite length/nuclei, a statistically significant reduction $(\mathrm{p}<0.01$, fig. 2Aiii).

Similarly, when protein $4.1 \mathrm{~N}$ expression is reduced via RNAi, neurite formation is impaired (fig. 2B). Confocal immunofluorescent labeling revealed $4.1 \mathrm{~N}$ and IP3R1 (inset, green) localization along cell extensions (mock and SCR, fig. 2Bi). However, when $4.1 \mathrm{~N}$ expression was decreased (fig. 2Bii), neurite formation was dramatically inhibited. When quantified, mock- and SCR-transfected cells exhibited $41.0 \pm 13.3$ and $36.0 \pm 9.0 \mu \mathrm{m}$ neurite length/nuclei, respectively, whereas sh4.1N-transfected cells averaged $11.5 \pm 2.2 \mu \mathrm{m}$ neurite length/nuclei, a statistically significant reduction ( $\mathrm{p}<0.05$, fig. 2Biii).

Neurite formation also was measured in cells with reduced expression of IP3 receptor type III (IP3R3), an isoform that does not interact with 4.1N [17], and does not have the same localization pattern as IP3R1 in PC12 cells [25] (fig. 2C). Under mock and SCR conditions, the localization of IP3R3 was within the soma, while IP3R1 (inset, green) extended into the neuronal processes (fig. 2Ci). However, when the expression of IP3R3 was reduced (fig. 2Cii), cells continued to form neurites with no difference among experimental conditions (fig. 2Ciii). Under mock, SCR, and shIP3R3 transfection conditions, cells averaged $35.6 \pm 3.9,35.9 \pm 19.0$, and $38.0 \pm 13.8$ $\mu \mathrm{m}$ neurite length/nuclei (difference not significant, fig. 2Ciii). These findings illustrate that expression of IP3R 1 and protein $4.1 \mathrm{~N}$, but not IP3R3, are necessary for neurite formation.

Expression of Soluble IP3R1 and Protein 4.1N Binding Regions Attenuates Neurite Formation

IP3R1 consists of multiple distinct functional domains including the IP3 binding site, internal coupling domain, transmembrane/channel domain, and the protein $4.1 \mathrm{~N}$ binding site [26] (fig. 3A). 4.1N has two major domains, the FERM (4.1, ezrin, radixin, moesin) domain, which allows for cytoskeletal targeting, and the IP3R1 binding region [18] (fig. 3A). These respective binding regions for IP3R1 and protein $4.1 \mathrm{~N}$ have been characterized previously and used to uncouple the interaction between these two proteins $[17,19,27]$. The soluble binding region of each protein was conjugated downstream of DsRed to generate dominant negative fusion proteins. PC12 cells transfected with these constructs were differentiated with NGF for $48 \mathrm{~h}$ to determine the role of the IP3R $1 / 4.1 \mathrm{~N}$ relationship in neurite formation. In cells transfected with DsRed alone, red fluorescence was distributed throughout the cytoplasm, and protein $4.1 \mathrm{~N}$ labeling was

IP3R1/4.1N Mediates Neurite Growth via $\mathrm{Ca}^{2+}$ Waves found in its usual location in the neurite process and at the cell periphery (fig. 3B). In contrast, DsRed conjugated to the soluble protein $4.1 \mathrm{~N}$ binding region of IP3R1 (DsRed-IP3R1 DN) strongly colocalized with endogenous protein $4.1 \mathrm{~N}$ along the plasma membrane (yellow). This colocalization is consistent with previous findings [18], and provides evidence that this fragment of IP3R1 prevents protein $4.1 \mathrm{~N}$ from targeting endogenous IP3R1 to the cell periphery. When comparing the morphology of cells transfected with DsRed alone to cells transfected with DsRed-IP3R1 DN, there was a significant reduction in neurite formation in IP3R1 DN-transfected cells. Under DsRed conditions, cells averaged $57.8 \pm 17.2 \mu \mathrm{m}$ neurite length/transfected cell, whereas cells transfected with the IP3R1 DN averaged $12.2 \pm 1.6 \mu \mathrm{m}$ neurite length/ transfected, a statistically significant reduction $(\mathrm{p}<0.01$, fig. 3D). Moreover, neurite formation was normal in nontransfected cells in close proximity to IP3R1 DN cells, providing further evidence that the IP3R 1 /protein $4.1 \mathrm{~N}$ interaction is important for neurite formation (fig. 3B).

Similar to what was observed in cells transfected with the IP3R1 DN, neurite formation was reduced in cells transfected with the IP3R1 binding region of protein 4.1N (DsRed-4.1N DN). In cells transfected with DsRed alone, red fluorescence was distributed throughout the cell and neurite formation was normal (fig. 3C). However, when the $4.1 \mathrm{~N}$ DN was introduced, colocalization of red fluorescence and IP3R1 (yellow) was observed and neurite formation was attenuated. Without the FERM domain, this protein chimera appeared to ineffectively target IP3R1 to the cell periphery, thus uncoupling the endogenous IP3R1/protein $4.1 \mathrm{~N}$ interaction and redistributing IP3R1 throughout the cytosol. This finding is consistent with previous work regarding the localization of IP3R1 in association with protein 4.1N [19]. In quantifying this phenotype, cells transfected with the $4.1 \mathrm{~N} \mathrm{DN}$ exhibited $26.1 \pm 2.2 \mu \mathrm{m}$ neurite length/transfected cell, which is a statistically significant reduction relative to DsRed alone, $57.8 \pm 17.2 \mu \mathrm{m}$ neurite length/transfected cell ( $p<0.05$, fig. $3 \mathrm{D})$. Together, these dominant negative studies provide evidence that the interaction between IP3R1 and protein $4.1 \mathrm{~N}$ is necessary for neurite formation.

\section{$\mathrm{Ca}^{2+}$ Waves Develop in PC12 Cells Stimulated with NGF}

To understand the functional significance of the IP3R1/protein $4.1 \mathrm{~N}$ relationship, we examined $\mathrm{Ca}^{2+}$ signaling events during neurite formation. At 0,24 , and 48 h of NGF differentiation, PC12 cells were stimulated 
A

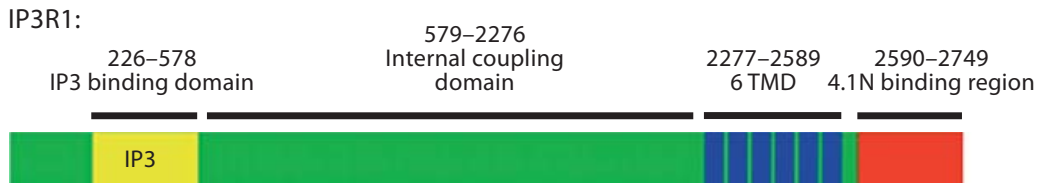

B
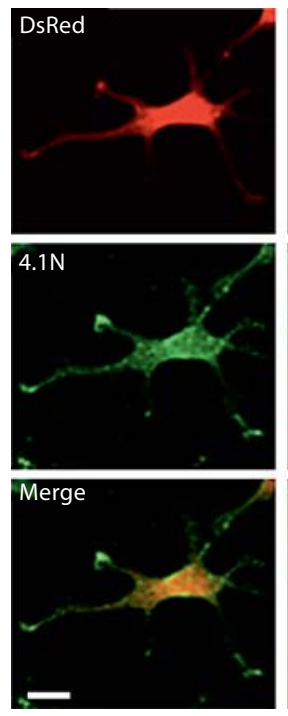
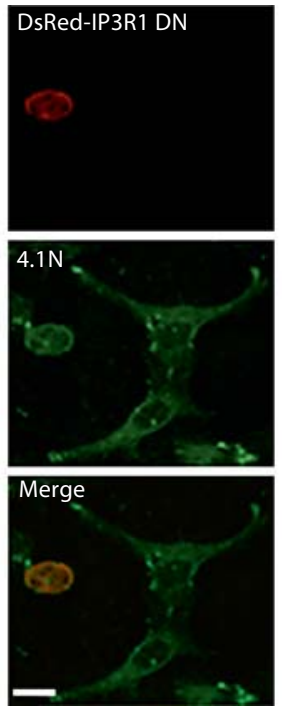

C
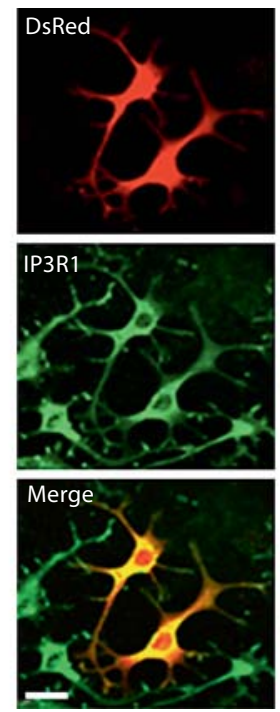

Protein 4.1N:

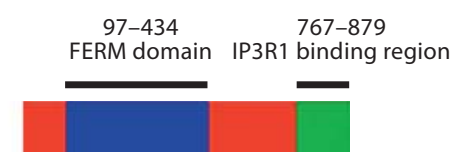

D
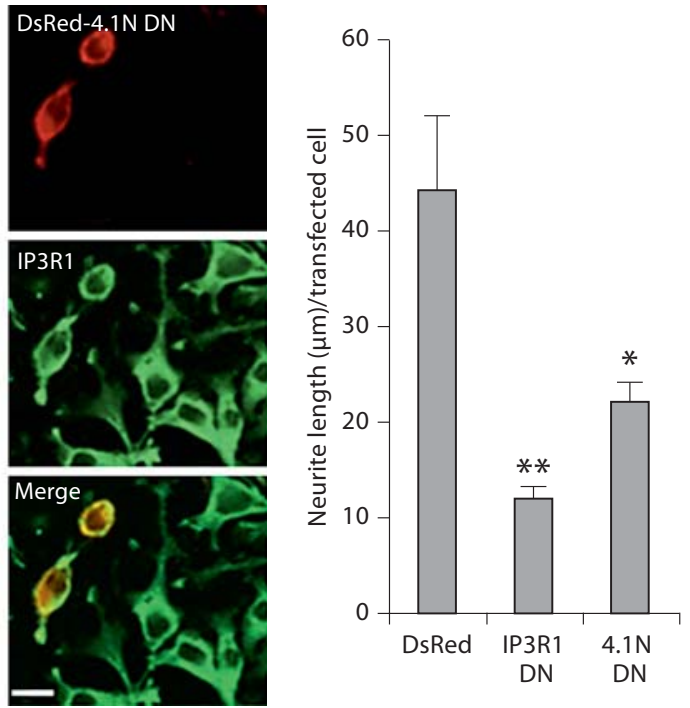

Fig. 3. Soluble protein $4.1 \mathrm{~N}$ and IP3R1 binding regions function as dominant negatives and attenuate neurite formation. A Cartoon diagram of IP3R1 and protein $4.1 \mathrm{~N}$ with labeled motifs and binding domains. B Confocal immunofluorescence images of PC12 cells stimulated with NGF for $48 \mathrm{~h}$ and transfected with DsRed alone (left) and IP3R1 dominant negative (IP3R1 DN) (right). DsRed alone is distributed diffusely throughout the cell and endogenous protein $4.1 \mathrm{~N}$ localizes along the cell periphery and in neurites. Cells expressing DsRed-IP3R1 DN retain a globular morphology and endogenous protein $4.1 \mathrm{~N}$ colocalizes with the fusion protein at the cell periphery (yellow). Nearby nontransfected cells retain wild-type morphology and protein $4.1 \mathrm{~N}$ localization. C Immunofluorescence images of PC12 cells stimulated

with the IP3-producing agonist $\mathrm{CCH}$, which can induce $\mathrm{Ca}^{2+}$ signals through either nicotinic or muscarinic receptors $[25,28]$. Both nicotinic- and muscarinic-mediated signaling events utilize intracellular $\mathrm{Ca}^{2+}$ stores and IP3Rs $[29,30]$. At these time points, expression of varying nicotinic receptor subunits shifts considerably, with declining levels of $\alpha 2$ and $\beta 4$, and increasing levels of $\beta 3$. Despite this, overall function of nicotinic receptors in PC12 cells does not appear to change in response to NGF [28]. The two PLC-coupled muscarinic isoforms with NGF for $48 \mathrm{~h}$ and transfected with DsRed alone (left) and protein $4.1 \mathrm{~N}$ dominant negative $(4.1 \mathrm{~N} \mathrm{DN})$ (right). DsRed alone is diffuse throughout the cell and endogenous IP3R1 is localized to both soma and neurites. Cells expressing DsRed-4.1N DN retain a globular morphology and endogenous IP3R1 colocalizes with the fusion protein in the cytoplasm (yellow). Nearby nontransfected cells retain wild-type morphology and IP3R1 localization. D Neurite quantification: average neurite lengths were $57.8 \pm 17.2,12.2 \pm 1.6$, and $26.1 \pm 2.2$ in cells expressing DsRed, IP3R $1 \mathrm{DN}$, and $4.1 \mathrm{~N} \mathrm{DN}$, respectively $\left({ }^{*} \mathrm{p}<0.05 ;{ }^{* *} \mathrm{p}<0.01 ; \mathrm{n}=\right.$ 3,150 cells assessed per experiment). Colors refer to the online version only.

expressed in PC12 cells, M1 and M5 [25, 31], maintain constant expression across all time points (online suppl. fig. 1; for all online supplementary material, see www. karger.com/doi/10.1159/000324507).

Prior to treatment with NGF and development of neurites (fig. 1D, 4Ai), stimulation with $50 \mu \mathrm{M} C \mathrm{CH}$ resulted in a uniform increase in $\mathrm{Ca}^{2+}$ throughout the cell (fig. 4Ai). This $\mathrm{Ca}^{2+}$ signaling pattern was quantified by comparing changes in Fluo-4 fluorescence intensity at central and peripheral ROIs. The $\mathrm{Ca}^{2+}$ signals in the central (purple) 
A i
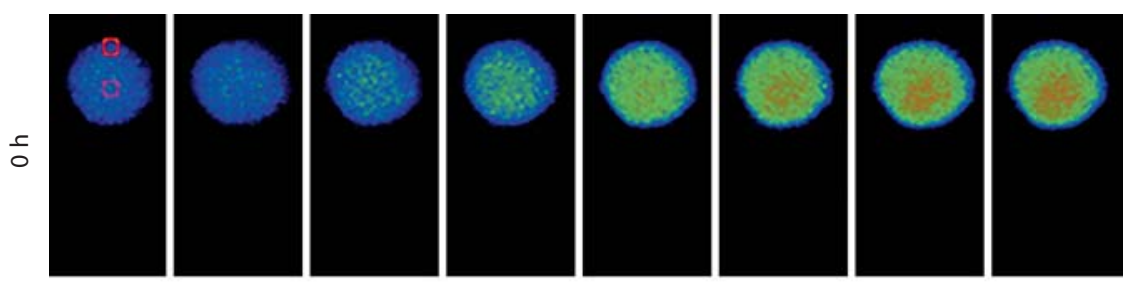

B i
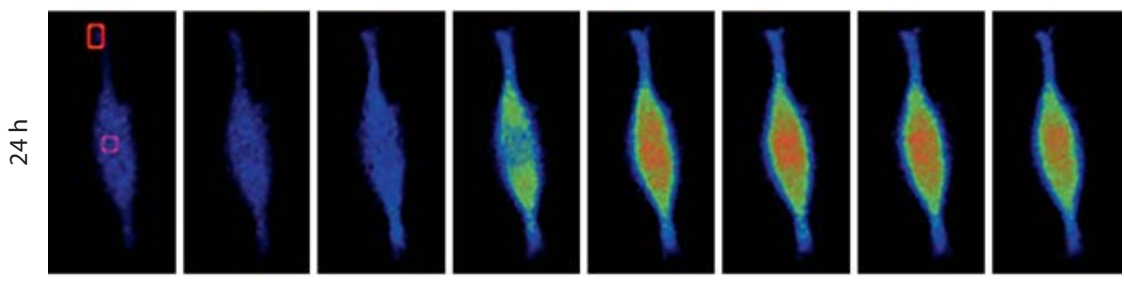

C i
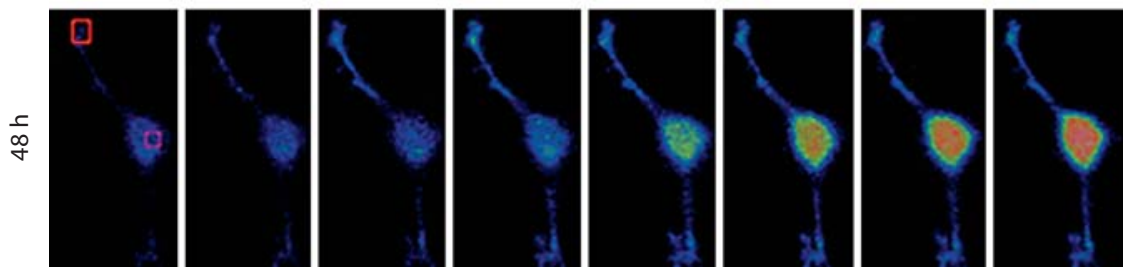
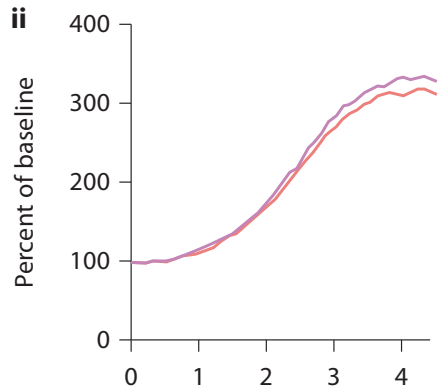

ii
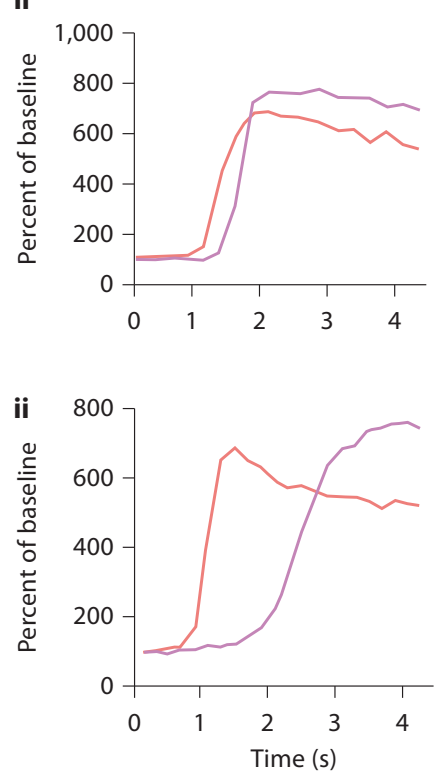

Fig. 4. $\mathrm{Ca}^{2+}$ signals in PC12 cells shift from homogeneous to waves during NGF differentiation. A PC12 cell $0 \mathrm{~h}$ after NGF stimulation and perfused with $50 \mu \mathrm{M} \mathrm{CCH}$ exhibits $\mathrm{Ca}^{2+}$ signals that are uniform throughout the cell. $\mathbf{i}$ Time lapse confocal images of a representative undifferentiated PC12 cell loaded with Fluo- 4 and perfused with $\mathrm{CCH}$. Signal amplitude was calculated as percent increase relative to baseline fluorescence using the equation $\Delta \mathrm{F}=$ $100 \% \times\left(\mathrm{F}-\mathrm{F}_{\mathrm{o}}\right) / \mathrm{F}_{\mathrm{o}}$. ii ROI intensities from periphery (red) and center (purple) of the cell, plotted against time. B Representative PC12 cell $24 \mathrm{~h}$ after NGF stimulation perfused with $50 \mu \mathrm{M} \mathrm{CCH}$ exhibits a $\mathrm{Ca}^{2+}$ wave. i Serial confocal images of a partially differentiated PC12 cell perfused with $\mathrm{CCH}$. ii ROI intensities from the budding neurite (red) and soma (purple) of the perfused cell. C PC12 cell $48 \mathrm{~h}$ after NGF stimulation perfused with $50 \mu \mathrm{M} \mathrm{CCH}$ exhibits a more pronounced $\mathrm{Ca}^{2+}$ wave. i Serial confocal images of a fully differentiated PC12 cell perfused with CCH. ii ROI intensities from the budding neurite (red) and soma (purple) of the perfused cell. The graph illustrates that the time delay as the $\mathrm{Ca}^{2+}$ wave spreads from neurite to soma is more pronounced than in the wave detected $24 \mathrm{~h}$ after NGF. Each of the three cells shown here is representative of what was observed in 15-30 separate cells under the same experimental conditions. Colors refer to the online version only.

lated with NGF for $48 \mathrm{~h}$ exhibited an even clearer neuriteto-soma wavelike pattern of $\mathrm{Ca}^{2+}$ release similar to what is observed in neurons, which initiates at the terminal end of neuronal extensions and propagates towards the soma (fig. 4Ci and online suppl. movie 3 ). At room temperature $\left(21^{\circ} \mathrm{C}\right)$ and $50 \mu \mathrm{M} \mathrm{CCH}$, these $\mathrm{Ca}^{2+}$ waves had a velocity of $\sim 25 \mu \mathrm{m} / \mathrm{s}$, which is consistent with previously observed kinetics in PC12 cells [25] and primary neu- 


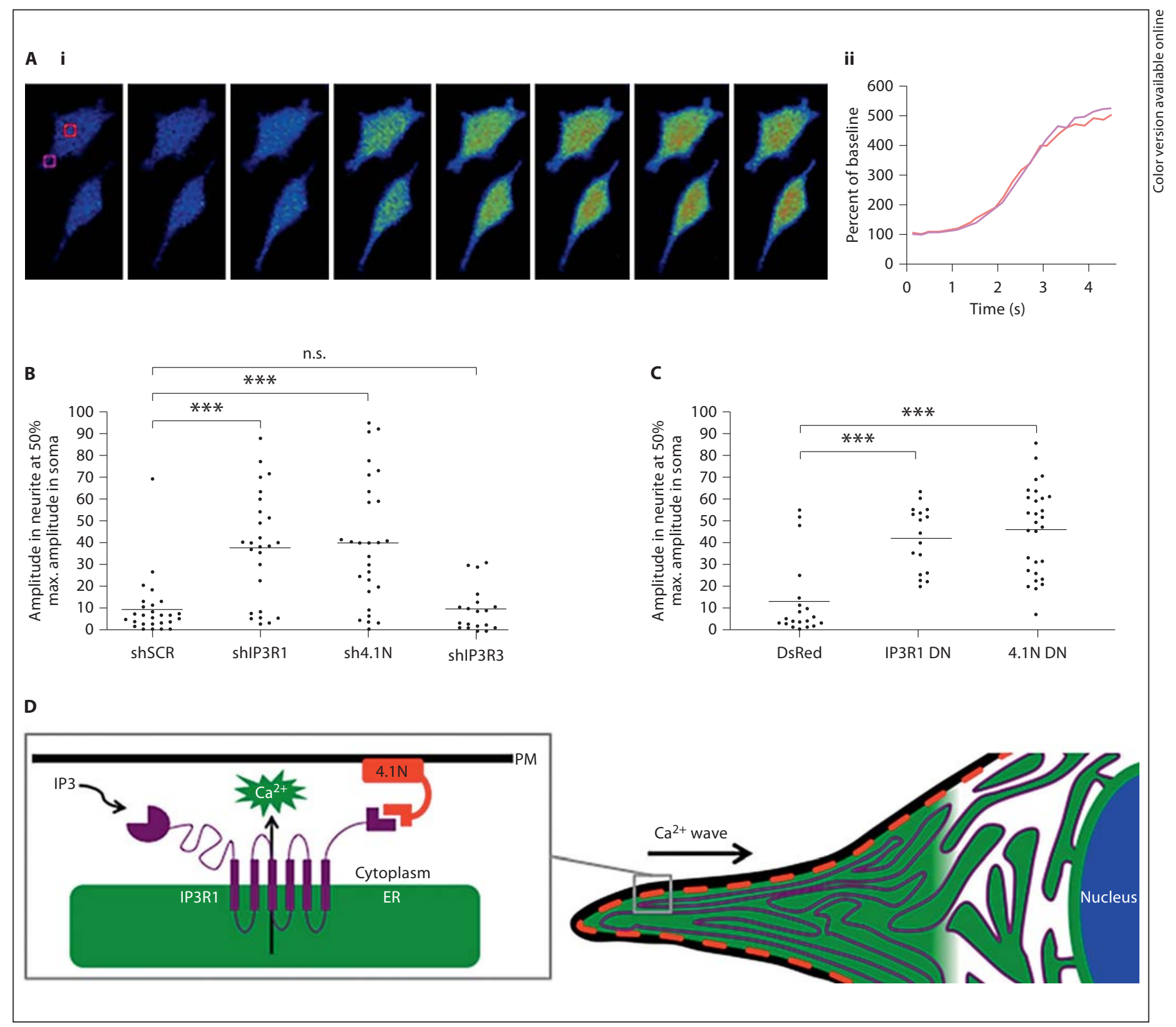

Fig. 5. Disruption of IP3R1/protein $4.1 \mathrm{~N}$ interaction by RNAi or dominant negative constructs alters $\mathrm{Ca}^{2+}$ signaling from a wave to a uniform pattern. A Example of two partially differentiated PC12 cells (24 h NGF) expressing DsRed-4.1N DN and perfused with $50 \mu \mathrm{M}$ CCH. i Serial confocal images of perfused cell displaying a homogeneous pattern of $\mathrm{Ca}^{2+}$ release. ii ROI intensities from the budding neurite (red) and soma (purple) of perfused cell, plotted against time. Signal amplitude was calculated as percent increase relative to baseline fluorescence using the equation $\Delta \mathrm{F}=$ $100 \% \times\left(\mathrm{F}-\mathrm{F}_{\mathrm{o}}\right) / \mathrm{F}_{\mathrm{o}}$. B Quantification of the amplitude of the $\mathrm{Ca}^{2+}$ signal in the soma when the neurite $\mathrm{Ca}^{2+}$ signal has reached $50 \%$ of its maximum value in cells transfected with SCR, IP3R1 (shIP3R1), protein $4.1 \mathrm{~N}$ (sh4.1N) or IP3R3 (shIP3R3) siRNA. Note that the average amplitude in the soma under control conditions (SCR and shIP3R3) is $\sim 10 \%$ of its maximum when the neurite
$\mathrm{Ca}^{2+}$ signals reaches $50 \%$ of its maximum amplitude, whereas sh4.1N- and shIP3R1-transfected cells reach an average amplitude in the soma of $\sim 40 \%$ of their maximum when the neurite $\mathrm{Ca}^{2+}$ signal reaches $50 \%$ of its maximum $\left({ }^{* *} \mathrm{p}<0.001\right)$. C Quantification of the amplitude of the $\mathrm{Ca}^{2+}$ signal in the soma when the neurite $\mathrm{Ca}^{2+}$ signal has reached $50 \%$ of its maximum in cells transfected with DsRed, IP3R1 DN, or 4.1N DN. Average amplitude in the soma of cells expressing DsRed alone is $\sim 10 \%$ of its maximum when the $\mathrm{Ca}^{2+}$ signal in the neurite has reached $50 \%$ of its maximum amplitude, whereas in IP3R1 DN- and 4.1N DNtransfected cells the average amplitude in the soma is $\sim 45 \%$ when the $\mathrm{Ca}^{2+}$ signal in the neurite has reached $50 \%$ of its maximum $\left({ }^{* * *} \mathrm{p}<0.001\right)$. D Cartoon diagram depicting functional role of IP3R1/protein $4.1 \mathrm{~N}$ relationship. Colors refer to the online version only. 
rons [32]. Therefore, in addition to neurite formation, a progressive shift in $\mathrm{Ca}^{2+}$ signaling, from a homogeneous to a spatially restricted wave pattern of release, in PC12 cells was induced by NGF stimulation. This transition state offered a framework to assess $\mathrm{Ca}^{2+}$ signaling patterns during the initial stages of neuronal development.

\section{Disruption of IP3R1/Protein 4.1N Binding Changes} $\mathrm{Ca}^{2+}$ Signals from a Wave to a Homogeneous Pattern in Partially Differentiated PC12 Cells

To investigate the functional role of the IP3R1/protein $4.1 \mathrm{~N}$ interaction in $\mathrm{Ca}^{2+}$ wave formation, previously used RNAi and dominant negative molecules were introduced during $\mathrm{CCH}$ perfusion experiments. Transfected PC12 cells were stimulated with NGF for $24 \mathrm{~h}$ to investigate cells in their morphological transition state. PC12 cells treated with these RNAi or dominant negative constructs exhibited homogeneous patterns of $\mathrm{Ca}^{2+}$ release, rather than spatially organized waves (fig. 5Ai and online suppl. movie 4). Using ROIs in the neurite (red) and somatic (yellow) areas of the cell, nearly superimposable patterns of $\mathrm{Ca}^{2+}$ release were observed (fig. 5Aii). Under control (SCR or IP3R3) RNAi conditions, the $\mathrm{Ca}^{2+}$ signal in the soma reached only $\sim 10 \%$ of its maximum when the signal in the neurite had reached $\sim 50 \%$ of its maximum amplitude (fig. 5B: horizontal lines), indicating the signals are distinct. However, when IP3R1 or protein $4.1 \mathrm{~N}$ expression was reduced via RNAi, the Fluo-4 fluorescence intensity in the soma reached $\sim 40 \%$ when the signal in the neurite had reached $\sim 50 \%$ of its maximum amplitude. This finding provides evidence that cells revert to a homogeneous pattern of $\mathrm{Ca}^{2+}$ release in the absence of IP3R1 or protein 4.1N (fig. 5B: horizontal lines). Significant differences in $\mathrm{Ca}^{2+}$ wave formation were observed between cells treated with SCR versus shIP3R1 and SCR versus sh $4.1 \mathrm{~N}$, but not between cells treated with SCR versus shIP3R3 (fig. 5B). Similar experiments were carried out with dominant negative constructs, using cells transfected with DsRed alone as a control. In cells transfected with DsRed alone, the $\mathrm{Ca}^{2+}$ signal in the soma reached only $\sim 10 \%$ of its maximum when the signal in the neurite had reached $\sim 50 \%$ of its maximum amplitude (fig. 5C: horizontal lines). In contrast, in cells transfected with either IP3R1 DN or $4.1 \mathrm{~N}$ DN, the Fluo-4 fluorescence intensity in the soma reached $\sim 45 \%$ when the signal in the neurite had reached $\sim 50 \%$ of its maximum amplitude (fig. 5C: horizontal lines). Significant differences in $\mathrm{Ca}^{2+}$ wave formation were observed between cells expressing DsRed alone versus either IP3R1 DN or 4.1N DN (fig. 5C). Taken together, these findings suggest

IP3R1/4.1N Mediates Neurite Growth via $\mathrm{Ca}^{2+}$ Waves that protein $4.1 \mathrm{~N}$ facilitates the positioning of IP3R1 along the cell periphery in neuronal tissue, allowing for the periphery to serve as the initiation site for $\mathrm{Ca}^{2+}$ waves (fig. 5D). This in turn suggests a functional role for the IP3R1/protein $4.1 \mathrm{~N}$ relationship. $\mathrm{Ca}^{2+}$ waves have been implicated in several cellular processes, including cell proliferation [33] and neuronal plasticity [11], and the current work provides evidence for the molecular basis of $\mathrm{Ca}^{2+}$ wave formation. This work also provides direct evidence that $\mathrm{Ca}^{2+}$ waves may in turn be responsible for a specific downstream event, neurite formation.

\section{Discussion}

IP3R1 is the principal intracellular $\mathrm{Ca}^{2+}$ release channel in neurons $[3,34,35]$. While other $\mathrm{Ca}^{2+}$ release channels, such as the ryanodine receptor and IP3R3, are expressed in neuronal cells [25], their role in $\mathrm{Ca}^{2+}$ wave formation is either minor [25] or nonexistent [33]. However, the behavior of IP3R1 is not determined solely by the channel itself. A number of binding partners influence IP3R1 activity as well as its subcellular distribution. Within the endoplasmic reticulum, chromogranin B modulates IP3R1 $\mathrm{Ca}^{2+}$ release by enhancing channel sensitivity [36] and determining signal initiation sites [37]. Similarly, in the cytoplasm neuronal calcium sensor 1 increases IP3-mediated channel activity of IP3R1 both in vitro and in vivo [38]. Moreover, the complex relationship between these binding partners and IP3R1 has been implicated in neurological disorders including schizophrenia and Alzheimer's disease (chromogranin B), and bipolar disease (neuronal calcium sensor 1) [39]. Structural proteins are also relevant and play a role in IP3R1 localization. Homerlb/c is a membrane-associated protein that mediates the relationship between IP3Rs and both TRPC1 [40] and group I metabotropic glutamate receptors [41]. In linking ER-embedded IP3Rs with plasma membrane proteins, gating behavior between internal and external $\mathrm{Ca}^{2+}$ stores can be coordinated, as can signaling cascades necessary for synaptic function. Protein $4.1 \mathrm{~N}$ interacts with IP3R1 directly [42] and localizes the receptor/channel to the subplasmalemmal space [17-19]. Further, while the interacting regions between these two proteins have previously been mapped [27], a functional role for this protein-protein interaction is not known. The current study took advantage of these known properties of IP3R 1 and protein $4.1 \mathrm{~N}$ to demonstrate that their interaction results in neurite-to-soma $\mathrm{Ca}^{2+}$ wave formation, and that this is associated with neurite development. 
The causal relationship between $\mathrm{Ca}^{2+}$ waves and neurite formation can be difficult to establish. To address this issue, we carried out experiments in partially differentiated PC12 cells (24-hour NGF stimulation). Under this condition, the morphological difference between control (mock, SCR, shIP3R3, DsRed) and treated cells (shIP3R1, sh4.1N, DN) is negligible (see fig. $4 \mathrm{Bi}$ vs. fig. $5 \mathrm{Ai}$ ). This observation suggests that at this stage of development the cell is primed for neurite formation, pending necessary signaling components such as $\mathrm{Ca}^{2+}$ wave machinery. However, despite this similarity in morphology across experimental conditions, $\mathrm{Ca}^{2+}$ signaling events are distinctly different, providing evidence that when these wave patterns of release are in place, neurite formation is possible. This conclusion is separate from the idea that these $\mathrm{Ca}^{2+}$ waves are important for a postdifferentiation function, such as neurite maintenance, because $\mathrm{Ca}^{2+}$ waves appear before full neurite development and if they do not, neurite formation will not occur. Further, while it is difficult at early stages of differentiation to distinguish a wave pattern of $\mathrm{Ca}^{2+}$ release from independent signaling events in different regions of the cell, previous studies involving CCH-stimulated PC12 cells $[25,43]$ and our 48-hour NGF stimulation data together suggest this $\mathrm{Ca}^{2+}$ transient is properly characterized as a wave.
How do $\mathrm{Ca}^{2+}$ waves affect neuronal growth? In primary neurons, IP3-mediated $\mathrm{Ca}^{2+}$ signals regulate growth cone navigation [44] and morphological integrity [3]. Given the spatially restricted nature of waves, separation of $\mathrm{Ca}^{2+}$ signals between neurite and soma could allow for independent signaling events in the cytoplasm and nucleus, a phenomenon observed in other cell types [45]. Distinct types of $\mathrm{Ca}^{2+}$ signals within the nucleus are important for processes such as gene expression [46] and cell proliferation [47]. Because NGF halts the cell cycle in PC12 cells [48], $\mathrm{Ca}^{2+}$ waves furthermore could regulate cell checkpoints, a role that has been described for other growth factors such as hepatocyte growth factor [21] and insulin [49]. The current work provides direct evidence that the molecular machinery responsible for organizing $\mathrm{Ca}^{2+}$ waves in neuronal cells is important for a specific downstream event, neurite formation.

\section{Acknowledgments}

We thank Pietro de Camili and Louise Lucast for providing PC12 cells, Thomas Biederer and Adam Fogel for primary hippocampal neurons, Barbara Ehrlich for IP3R1 cDNA and Ilya Bezprozvanny for protein $4.1 \mathrm{~N}$ cDNA. This work was supported by NIH grants DK45710, DK57751, DK61747, and DK34989.

\section{References}

1 Sun J, Pang ZP, Qin D, Fahim AT, Adachi R, Sudhof TC: A dual-Ca2+-sensor model for neurotransmitter release in a central synapse. Nature 2007;450:676-682.

-2 Fernández-Chacón R, Königstorfer A, Gerber SH, Garcia J, Matos MF, Stevens CF, Brose N, Rizo J, Rosenmund C, Südhof TC: Synaptotagmin I functions as a calcium regulator of release probability. Nature 2001; 410:41-49.

3 Takei K, Shin RM, Inoue T, Kato K, Mikoshiba K: Regulation of nerve growth mediated by inositol 1,4,5-trisphosphate receptors in growth cones. Science 1998;282: $1705-1708$

-4 Iketani M, Imaizumi C, Nakamura F, Jeromin A, Mikoshiba K, Goshima Y, Takei K: Regulation of neurite outgrowth mediated by neuronal calcium sensor-1 and inositol 1,4,5-trisphosphate receptor in nerve growth cones. Neuroscience 2009;161:743-752.

5 Bading $\mathrm{H}$, Hardingham GE, Johnson CM, Chawla S: Gene regulation by nuclear and cytoplasmic calcium signals. Biochem Biophys Res Commun 1997;236:541-543.
6 Webb SE, Miller AL: Calcium signalling during embryonic development. Nat Rev Mol Cell Biol 2003;4:539-551.

7 Berridge MJ, Lipp P, Bootman MD: The versatility and universality of calcium signalling. Nat Rev Mol Cell Biol 2000;1:11-21.

8 Nathanson MH, Fallon MB, Padfield PJ, Maranto AR: Localization of the type 3 inositol 1,4,5-trisphosphate receptor in the $\mathrm{Ca} 2+$ wave trigger zone of pancreatic acinar cells. J Biol Chem 1994;269:4693-4696.

-9 Hagar RE, Burgstahler AD, Nathanson MH, Ehrlich BE: Type III InsP3 receptor channel stays open in the presence of increased calcium. Nature 1998;396:81-84.

10 Hernandez E, Leite MF, Guerra MT, Kruglov EA, Bruna-Romero O, Rodrigues MA, Gomes DA, Giordano FJ, Dranoff JA, Nathanson MH: The spatial distribution of inositol 1,4,5-trisphosphate receptor isoforms shapes Ca2+ waves. J Biol Chem 2007;282: 10057-10067.

11 Barbara JG: Ip3-dependent calcium-induced calcium release mediates bidirectional calcium waves in neurones: functional implications for synaptic plasticity. Biochim Biophys Acta 2002;1600:12-18.
12 Kume S, Saneyoshi T, Mikoshiba K: Desensitization of IP3-induced $\mathrm{Ca} 2+$ release by overexpression of a constitutively active Gqalpha protein converts ventral to dorsal fate in Xenopus early embryos. Dev Growth Differ 2000;42:327-335.

$13 \mathrm{Gu}$ X, Spitzer NC: Breaking the code: regulation of neuronal differentiation by spontaneous calcium transients. Dev Neurosci 1997; 19:33-41.

14 Wallingford JB, Ewald AJ, Harland RM, Fraser SE: Calcium signaling during convergent extension in Xenopus. Curr Biol 2001;11: 652-661.

15 Kasai H, Augustine GJ: Cytosolic Ca2+ gradients triggering unidirectional fluid secretion from exocrine pancreas. Nature 1990; 348:735-738.

16 Nagata J, Guerra MT, Shugrue CA, Gomes DA, Nagata N, Nathanson MH: Lipid rafts establish calcium waves in hepatocytes. Gastroenterology 2007;133:256-267.

17 Maximov A, Tang TS, Bezprozvanny I: Association of the type 1 inositol $(1,4,5)$-trisphosphate receptor with $4.1 \mathrm{n}$ protein in neurons. Mol Cell Neurosci 2003;22:271283. 


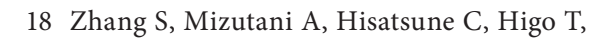
Bannai H, Nakayama T, Hattori M, Mikoshiba K: Protein $4.1 \mathrm{~N}$ is required for translocation of inositol 1,4,5-trisphosphate receptor type 1 to the basolateral membrane domain in polarized Madin-Darby canine kidney cells. J Biol Chem 2003;278:40484056.

-19 Fukatsu K, Bannai H, Zhang S, Nakamura H, Inoue T, Mikoshiba K: Lateral diffusion of inositol 1,4,5-trisphosphate receptor type 1 is regulated by actin filaments and $4.1 \mathrm{~N}$ in neuronal dendrites. J Biol Chem 2004;279: 48976-48982.

-20 Sehgal S, Guerra MT, Kruglov EA, Wang J, Nathanson MH: Protein $4.1 \mathrm{~N}$ does not interact with the inositol 1,4,5-trisphosphate receptor in an epithelial cell line. Cell Calcium 2005;38:469-480.

-21 Gomes DA, Rodrigues MA, Leite MF, Gomez MV, Varnai P, Balla T, Bennett AM, Nathanson MH: c-Met must translocate to the nucleus to initiate calcium signals. J Biol Chem 2008;283:4344-4351.

-22 Obara Y, Yamauchi A, Takehara S, Nemoto W, Takahashi M, Stork PJ, Nakahata N: ERK5 activity is required for nerve growth factor-induced neurite outgrowth and stabilization of tyrosine hydroxylase in $\mathrm{PC} 12$ cells. J Biol Chem 2009;284:23564-23573.

-23 Greene LA, Tischler AS: Establishment of a noradrenergic clonal line of rat adrenal pheochromocytoma cells which respond to nerve growth factor. Proc Natl Acad Sci USA 1976;73:2424-2428.

24 Ye K, Compton DA, Lai MM, Walensky LD, Snyder SH: Protein $4.1 \mathrm{~N}$ binding to nuclear mitotic apparatus protein in PC12 cells mediates the antiproliferative actions of nerve growth factor. J Neurosci 1999;19:1074710756.

-25 Johenning FW, Zochowski M, Conway SJ, Holmes AB, Koulen P, Ehrlich BE: Distinct intracellular calcium transients in neurites and somata integrate neuronal signals. J Neurosci 2002;22:5344-5353.

26 Mikoshiba K: IP3 receptor/Ca2+ channel: from discovery to new signaling concepts. J Neurochem 2007;102:1426-1446.

-27 Fukatsu K, Bannai H, Inoue T, Mikoshiba K: $4.1 \mathrm{~N}$ binding regions of inositol 1,4,5-trisphosphate receptor type 1 . Biochem Biophys Res Commun 2006;342:573-576.

-28 Rogers SW, Mandelzys A, Deneris ES, Cooper E, Heinemann S: The expression of nicotinic acetylcholine receptors by PC12 cells treated with NGF. J Neurosci 1992;12:46114623.
29 Dajas-Bailador FA, Mogg AJ, Wonnacott S: Intracellular $\mathrm{Ca} 2+$ signals evoked by stimulation of nicotinic acetylcholine receptors in SH-SY5Y cells: contribution of voltage-operated $\mathrm{Ca} 2+$ channels and $\mathrm{Ca} 2+$ stores. J Neurochem 2002;81:606-614.

30 Sharma G, Vijayaraghavan S: Nicotinic cholinergic signaling in hippocampal astrocytes involves calcium-induced calcium release from intracellular stores. Proc Natl Acad Sci USA 2001;98:4148-4153.

31 Berkeley JL, Levey AI: Muscarinic activation of mitogen-activated protein kinase in $\mathrm{PC} 12$ cells. J Neurochem 2000;75:487-493.

32 Power JM, Sah P: Nuclear calcium signaling evoked by cholinergic stimulation in hippocampal CA1 pyramidal neurons. J Neurosci 2002;22:3454-3462.

33 Weissman TA, Riquelme PA, Ivic L, Flint AC, Kriegstein AR: Calcium waves propagate through radial glial cells and modulate proliferation in the developing neocortex. Neuron 2004;43:647-661.

34 Furuichi T, Yoshikawa S, Miyawaki A, Wada K, Maeda N, Mikoshiba K: Primary structure and functional expression of the inositol 1,4,5-trisphosphate-binding protein $\mathrm{P} 400$. Nature 1989;342:32-38.

35 Wojcikiewicz RJ: Type I, II, and III inositol 1,4,5-trisphosphate receptors are unequally susceptible to down-regulation and are expressed in markedly different proportions in different cell types. J Biol Chem 1995;270: 11678-11683.

- 36 Thrower EC, Choe CU, So SH, Jeon SH, Ehrlich BE, Yoo SH: A functional interaction between chromogranin $\mathrm{B}$ and the inositol 1,4,5-trisphosphate receptor/Ca2+ channel. J Biol Chem 2003;278:49699-49706.

37 Jacob SN, Choe CU, Uhlen P, DeGray B, Yeckel MF, Ehrlich BE: Signaling microdomains regulate inositol 1,4,5-trisphosphatemediated intracellular calcium transients in cultured neurons. J Neurosci 2005;25:28532864.

- 38 Schlecker C, Boehmerle W, Jeromin A, DeGray B, Varshney A, Sharma Y, Szigeti-Buck K, Ehrlich BE: Neuronal calcium sensor-1 enhancement of InsP3 receptor activity is inhibited by therapeutic levels of lithium. J Clin Invest 2006;116:1668-1674.

-39 Choe CU, Ehrlich BE: The inositol 1,4,5-trisphosphate receptor (IP3R) and its regulators: sometimes good and sometimes bad teamwork. Sci STKE 2006;2006:re15.
40 Yuan JP, Kiselyov K, Shin DM, Chen J, Shcheynikov N, Kang SH, Dehoff $\mathrm{MH}$, Schwarz MK, Seeburg PH, Muallem S, Worley PF: Homer binds TRPC family channels and is required for gating of TRPC1 by IP3 receptors. Cell 2003;114:777-789.

41 Mao L, Yang L, Tang Q, Samdani S, Zhang G, Wang JQ: The scaffold protein Homerlb/c links metabotropic glutamate receptor 5 to extracellular signal-regulated protein kinase cascades in neurons. J Neurosci 2005;25: 2741-2752.

-42 Yamakawa H, Ohara R, Nakajima D, Nakayama M, Ohara O: Molecular characterization of a new member of the protein 4.1 family (brain 4.1) in rat brain. Brain Res Mol Brain Res 1999;70:197-209.

43 Lorenzon P, Zacchetti D, Codazzi F, Fumagalli G, Meldolesi J, Grohovaz F: Ca2+ waves in PC12 neurites: a bidirectional, receptororiented form of $\mathrm{Ca} 2+$ signaling. J Cell Biol 1995; 129:797-804.

44 Akiyama H, Matsu-ura T, Mikoshiba K, Kamiguchi $\mathrm{H}$ : Control of neuronal growth cone navigation by asymmetric inositol 1,4,5-trisphosphate signals. Sci Signal 2009;2:ra34.

45 Leite MF, Thrower EC, Echevarria W, Koulen P, Hirata K, Bennett AM, Ehrlich BE, Nathanson MH: Nuclear and cytosolic calcium are regulated independently. Proc Natl Acad Sci USA 2003;100:2975-2980.

46 Hardingham GE, Chawla S, Johnson CM, Bading H: Distinct functions of nuclear and cytoplasmic calcium in the control of gene expression. Nature 1997;385:260-265.

47 Rodrigues MA, Gomes DA, Leite MF, Grant W, Zhang L, Lam W, Cheng YC, Bennett AM, Nathanson MH: Nucleoplasmic calcium is required for cell proliferation. J Biol Chem 2007;282:17061-17068.

48 Yan GZ, Ziff EB: NGF regulates the PC12 cell cycle machinery through specific inhibition of the Cdk kinases and induction of cyclin D1. J Neurosci 1995;15:6200-6212.

49 Rodrigues MA, Gomes DA, Andrade VA, Leite MF, Nathanson MH: Insulin induces calcium signals in the nucleus of rat hepatocytes. Hepatology 2008;48:1621-1631.

50 Matus-Leibovitch N, Mengod G, Oron Y: Kinetics of the functional loss of different muscarinic receptor isoforms in Xenopus oocytes. Biochem J 1992;285:753-758.

51 Caccamo A, Oddo S, Billings LM, Green KN, Martinez-Coria H, Fisher A, LaFerla FM: M1 receptors play a central role in modulating AD-like pathology in transgenic mice. Neuron 2006;49:671-682. 